\title{
Extradural diamorphine in the control of pain following lumbar laminectomy
}

\author{
PJ TEDDY,* CBT ADAMS, ${ }^{*}$ M BRIGGS, * MA JAMOUS, * JH KERR†
}

From the Departments of Neurological Surgery* and of Anaesthetics, $\dagger$ The Radcliffe Infirmary, Oxford, UK

SUMMARY Catheters were inserted into the extradural space under direct vision at the time of surgery for prolapsed intervertebral disc or lumbar canal stenosis. In the post-operative period, diamorphine ( $3 \mathrm{mg}$ in $5 \mathrm{ml}$ water) was injected through the catheter when patients requested analgesia. In only four of 49 patients was significant pain relief not achieved after extradural diamorphine injection. In four other patients it was not possible to use this method of analgesia throughout the two post-operative days as planned. As judged by the improved mobility and by grading on a linear analogue pain scale, the quality of analgesia achieved was better than after intramuscular papaveretum (10-20 $\mathrm{mg})$ and extradural diamorphine was requested less frequently. There were no serious side-effects in the patients studied, although the technique was not used in patients over 55 years of age. Extradural diamorphine appeared to be less effective in two patients who had undergone re-explorations.

The commonest method of providing pain relief after major surgery has been by the parenteral administration of narcotic analgesics, although dissatisfaction is often expressed with the quality and persistence of the analgesia provided. ${ }^{1}$ In a few patients, local anaesthetics have been employed either by infiltration around peripheral nerves or plexuses or by injection into the extradural or subdural space. Use of these methods has been limited by technical difficulties, by the relative brevity of analgesic action and, in some instances, by cardiovascular side-effects. ${ }^{1}$

In recent years a fresh approach to the problem of pain relief has been suggested following the demonstration of opiate receptors in the brain and substantia gelatinosa of the spinal cord. ${ }^{2}$ Very small doses of opiates, placed in the extradural space, have been shown to traverse the meninges and to produce analgesia by acting on the spinal cord. ${ }^{34}$ Sympathetic nerves appear to be unaffected so that cardiovascular changes after the procedure are minimal ${ }^{5}$ but ventilatory depression probably caused by the direct action of the opiate on the respiratory centre has been observed occasionally. ${ }^{6-9}$

Address for reprint requests: PJ Teddy, Department of Neurological Surgery, Radcliffe Infirmary, Oxford OX2 6HE, UK.

Received 6 August 1981

Accepted 29 August 1981
Reports on the efficacy of extradural opiates in producing analgesia have often been enthusiastic, albeit in small numbers of patients. Excellent and prolonged analgesia has been obtained after various operations on the trunk and lower limbs, ${ }^{8-16}$ in chronic lower limb pains, ${ }^{17}$ and after multiple rib fractures ${ }^{18}$ but less satisfactory results occurred in childbirth ${ }^{15}{ }^{19-21}$ and after hysterectomy. ${ }^{22}$ Some of these differences may be related to the variety of agents and diluents, and to the range of doses and dilutions employed in different studies as well as to the different types of pain treated.

Judging by the results of a study of the effects of lumbar laminectomy wound infiltrations with bupivicaine, ${ }^{23}$ many patients experience severe back pain after this operation which is poorly controlled by conventional intramuscular opiate injections. Since the extradural space is readily accessible at laminectomy, it seemed likely that the extradural route could be used to provide more effective post-operative analgesia. This paper describes the effects of extradural diamorphine in the initial two days after laminectomy and includes a comparison of the analgesic effects with those of intramuscular papaveretum.

\section{Patients}

Analgesia from extradural diamorphine was considered for patients undergoing laminectomy for clinically and 1074 
radiologically suspected prolapsed lumbar intervertebral disc or lumbar spinal canal stenosis. Patients aged over 55 years or under 15 years were excluded, as were those with a past history of significant cardiac or respiratory disease or a known hypersensitivity to opiate analgesics. Extradural catheters were not inserted into patients who, at operation, were suspected of having CSF leaks through dural defects.

\section{Methods}

Before operation, patients were fully informed about the procedure by which analgesics could be obtained in the post-operative period. They were told that in the initial two days after operation analgesic drugs would be offered when required via an extradural catheter placed at operation rather than by the normal intramuscular route. Each patient was shown a $20 \mathrm{~cm}$ linear analogue pain scale ${ }^{24}$ upon which the left-hand end represented no pain and the right-hand end represented the most severe pain imaginable and they were asked to indicate the severity of back and leg pain whilst lying quietly in bed and after turning. In addition, they were asked whether they would provide similar assessments of pain in the post-operative period.

Most patients received a papaveretum/hyoscine premedication about one hour before operation. General anaesthesia was induced with a barbiturate, paralysis with curare or pancuronium and endo-tracheal anaesthesia maintained with oxygen, nitrous oxide and either trichoroethylene $(0 \cdot 2-0.5 \%)$ or intermittent fentanyl injections. The operation was carried out with the patient in the prone position on a Wilson frame. Before incision, in most patients the skin (but not deep fascia or paravertebral muscles) was infiltrated with a haemastatic solution of lignocaine $0.5 \%$ and adrenaline 1 in 200000 . A hemilaminectomy and disc exenteration was carried out for prolapsed disc and bilateral laminectomy (at one or more levels) for spinal canal stenosis. Before wound closure, a Tuohy epidural cannula was inserted through skin some $4 \mathrm{~cm}$ lateral to the wound and directed through the muscles to emerge deep in the wound. An 18 gauge epidural catheter was inserted through the cannula and passed into the epidural space under direct vision until the tip lay about $5 \mathrm{~cm}$ above the upper margin of the laminectomy. The cannula was withdrawn and, in the majority of cases, a suction drain inserted into the opposite side of the wound. The amount of fat in the extradural space was noted and recorded as more than average, average, or less than average. After wound closure, the epidural catheter was led over the patient's shoulder and taped securely to the skin along its entire length. A bacteriostatic micropore filter was attached to the free end and the catheter was flushed through with sterile normal saline. After recovery from anaesthesia and return to the post-operative ward, the patient was asked to indicate the severity of his pain on the linear analogue scale after which the suction drain (if present) was clamped off and $3 \mathrm{mg}$ of diamorphine sulphate in $5 \mathrm{ml}$ sterile water were injected through the extradural catheter by a member of the medical staff. Further assessments of the severity of pain were made at $\frac{1}{2}$ hour,
1 hour and 2 hours after injection. Extradural diamorphine was repeated, if required, after an interval of 3 hours from the previous injection. Alternative parenteral analgesia in the form of im injections of opiates was given only if the extradural diamorphine was ineffective, or on occasions when a member of the medical staff was not immediately available. Pain was assessed with analogue scorings after all im injections.

The time, route and dosage of all analgesic drugs were noted, as was the occurrence of technical complications such as the catheter blockage or displacement and of drug side effects such as respiratory depression, pruritis, nausea, hypertension and difficulty in starting micturition. The extradural catheter was removed about 48 hours after operation and the tip sent for microbiological examination. The incidence of wound infection and of delayed wound healing was also noted.

\section{Results}

\section{PATIENTS}

Data were collected over a five month period from 60 consecutive patients who presented for lumbar laminectomy. Six patients were not considered for extradural catheterisation (three because they were over 55 years of age, one with an atrial septal defect and two with suspected breaches of the dura mater) but catheters were inserted in the remaining 54 patients. Of these 54 patients, 32 were male, the average age was 40 years (range 16-55) and the mean weight was $69 \mathrm{~kg}$ (range $45-99 \mathrm{~kg}$ ). At operation, 47 were found to have prolapsed intervertebral discs (including one recurrent and one re-explored disc), three lumbar stenoses and four had negative explorations. Five of these patients did not receive extradural diamorphine (two did not request any postoperative analgesia, one man failed to breathe adequately following anaesthesia and was ventilated for three hours, and in two patients the catheters were found to be dislodged or blocked on return to the ward) but the remaining 49 patients received at least one injection.

\section{ANALGESIA}

Forty-five of the 49 patients expressed satisfaction with the analgesia produced by extradural diamorphine and this was corroborated both by the reduction in analogue pain scores and by the observations of nursing and medical staff. Four patients derived no relief of back pain following extradural injections, although one of these patients also denied significant lessening of pain after large amounts of intramuscular (im) papaveretum.

Neither the reduction in analogue pain scores after extradural diamorphine nor the intervals between injections appeared to be correlated with either the patient's weight (diamorphine dosage 
ranged from 0.3 to $0.7 \mu \mathrm{g} / \mathrm{kg}$ body weight) or the estimated amount of extrathecal fat.

\section{SIDE EFFECTS}

There were untoward effects in four patients. The most disturbing incident occurred in a 54 year old man: two hours after the initial extradural injection of $3 \mathrm{mg}$ diamorphine, his respiratory rate fell gradually to $6 /$ minute, although there was no impairment in conscious level. Naloxone $(0.2 \mathrm{mg})$ was given intravenously without any apparent effect but the respiratory rate increased spontaneously to normal levels over the next two hours and further progress was uneventful, although no further extradural injections of diamorphine were given. A second patient complained of severe pain during the first extradural injection and in two others the catheters blocked after the initial injection. Each of these patients had his catheter removed immediately and subsequent analgesia was provided with intramuscular papaveretum. One further patient developed catheter blockage after her second extradural injection but was able to obtain adequate pain relief thereafter with oral analgesics. One patient was re-explored during the period of the trial. After the first operation he obtained excellent pain relief within a few minutes of extradural diamorphine which lasted an average of seven hours. Although he obtained adequate pain relief following the second procedure, he felt that the injections were not as successful as after the first operation and this was reflected in his analogue pain scores. One of the four patients who had no pain relief had undergone re-exploration for recurrent disc prolapse. Five patients complained of generalised headache about two hours after extradural diamorphine and four complained of discomfort whilst injections were being administered. There was an increase in the period between operation and the voiding of urine which was more marked in the male patients but no patient required urinary catheterisation. No patient complained of pruritis and nausea and vomiting were infrequent.

Micro-organisms were not cultured from any of the extradural catheter tips and there were no cases of wound infection or of delayed wound healing. At follow-up six weeks to three months after operation, there was no indication that the operative results were any less satisfactory than in those patients who had received im papaveretum for post-operative analgesia.

COMPARISON OF EXTRADURAL

DIAMORPHINE WITH INTRAMUSCULAR

PAPAVERETUM

The analgesic effects of $3 \mathrm{mg}$ of diamorphine injected into the extradural space were compared with those of $10-20 \mathrm{mg}$ of papaveretum injected intramuscularly after lumbar laminectomy. In addition to the analogue pain scores obtained after im injections from patients who, for various reasons, were not given extradural diamorphine, similar data were available from a group of patients in whom a recent study of wound infiltration with bupivicaine after the same operation had been carried out. ${ }^{23}$ These 46 patients showed similar sex distribution, mean age, mean weight and pathology, but pain analogue scores had been collected for only the initial 24 hours post-operatively. In total, therefore, pain analogue scores after 297 intramuscular injections in 56 patients were available for comparison with those after 206 extradural injections in 49 patients. In the initial 24 hours, the mean reduction in the analogue score for back pain after extradural diamorphine was 7.4 (SD 1.7) while that after im papaveretum was significantly less 3.6 (SD 1.8). After operation, analogue scores for leg pain were generally much lower than for back pain and there was no significant change after the two modes of analgesia. The $3 \mathrm{mg}$ dose of diamorphine used appeared to induce less drowsiness than the intramuscular opiate and turning in bed was noted by both patients and nursing staff to be much easier after the extradural injections. Those patients who received analgesia by both routes commented on the greater efficacy and feeling of well-being after the extradural injections. The average number of extradural injections required in the first 24 hours after operation was 3.4 and in 48 hours 4.2 (range 1-6). Patients given intramuscular papaveretum required an average of 5.3 injections in the first 24 hours and 7.8 in 48 hours (range 2-9). By this time, most patients had been able to convert to oral analgesics such as paracetamol or Distalgesic. After extradural injections, adequate levels of analgesia were generally achieved within 30 minutes and there was often a further fall in analogue pain scores over the subsequent half hour which were well maintained over the next hour (fig). Further extradural top-ups were usually requested at intervals of six to seven hours and this interval did not shorten with successive injections even though patients were much more mobile on the second post-operative day. After intramuscular injections, minimal pain scores were usually apparent 30 minutes later, but it is noteworthy that scores had often almost returned to pre-injection levels within two hours (fig).

Discussion

Ideal post-operative analgesia should remove severe 


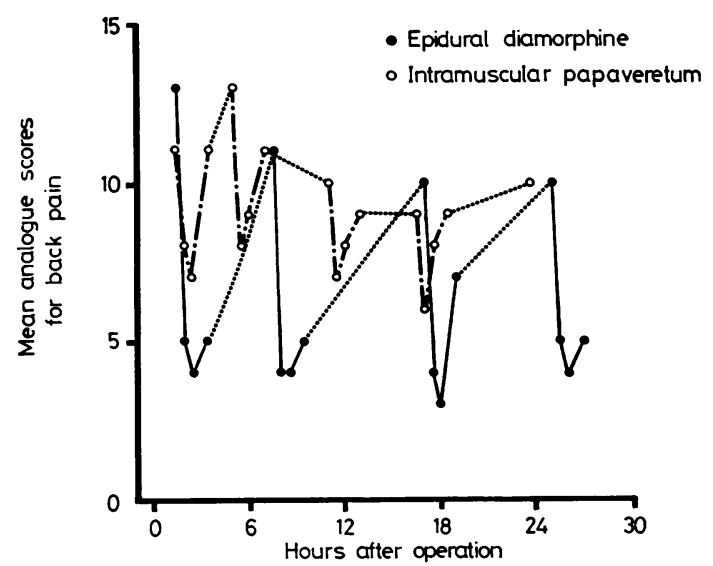

Fig Comparison of analgesia produced by extradural diamorphine in 49 patients and intramuscular papaveretum in 56 patients following lumbar laminectomy. Mean pain analogue scores for back pain before, $\frac{1}{2} 1$ and 2 hours after injection are plotted at average times for successive injections.

pain but allow the patient to be alert and mobile. Parenteral opiates in effective analgesic doses do not leave patients particularly alert or mobile even if the staffing levels in the post-operative ward allowed drugs to be given in the best way, which is frequently and in small doses. Instead, infrequent and large doses are usually given so that patients fluctuate between drowsy analgesic immobility and tense painful immobility. It seemed to us that epidural opiates might allow the ideal post-operative analgesia to be more nearly achieved after laminectomy since there have been many reports in recent years of their use to relieve pain in the trunk and lower limbs. ${ }^{7-16}$ The technique appeared particularly appropriate following lumbar laminectomy because the catheter can be placed precisely and with little risk of dural puncture or infection. Although the effect of blood and serous fluid in the extradural space upon the development of analgesia was unknown, diffusion of the opiate into the cerebrospinal fluid does not appear to have been impaired and the only practical effect appears to have been to increase the incidence of catheter blockage. This problem has been minimised recently by filling the catheter with normal saline immediately after insertion and by refilling whenever any blood stained fluid appears within it.

Diamorphine was used in this study partly because of satisfactory local experience after total hip replacement and in chronic pain ${ }^{25}$ and partly because it is normally supplied in a pure form. Subsequent disappointing reports with morphine in the extra- dural space following hysterectomy and in labour have tended to confirm this preference..$^{15-22}$ Because of respiratory depression following the administration of $5 \mathrm{mg}$ diamorphine to elderly patients following total hip replacement, it was decided to limit the dose to $3 \mathrm{mg}$ in the first instance and to avoid its use in patients over 55 years of age. In the current total experience of some 80 patients, there has been only one significant respiratory episode and, since this patient's bradypnoea was unaffected by intravenous naloxone, it is debatable whether the diamorphine should be considered responsible. ${ }^{5-7}$

Extradural diamorphine injections provided excellent pain relief after lumbar laminectomy in 45 of 49 patients described in this study. The overriding impression of both medical and nursing staff was that the pain relief obtained was superior to that produced following intramuscular papaveretum; the patients were more comfortable, less sleepy and easier to nurse; many, for example, were able to turn themselves in bed. These impressions were reflected in the pain analogue scores, the "extradural" group having consistently lower scores for the two hours following injection than those from patients who had received intramuscular papaveretum. Many fewer extradural injections were requested for an apparently better quality of pain control, although rather smoother analgesia could perhaps be achieved by more frequent top-ups. It has been suggested that injections of normal saline into the extradural space were as effective in producing analgesia after hysterectomy as extradural morphine. ${ }^{22}$ This was not the case in two of our patients who were given $5 \mathrm{ml}$ of normal saline by extradural injection on two occasions, then after analogue scoring at 30 minutes given $3 \mathrm{mg}$ diamorphine by the same route. Each reported no pain relief whatever after the injections of saline but substantial relief after the diamorphine. We did not think it justifiable to repeat this procedure since McQuay25 has also reported a similar positive response to diamorphine injections.

We would like to thank the nursing staff of Nuffield I Ward at the Radcliffe Infirmary for their cooperation and help during this study.

\section{References}

${ }^{1}$ Utting JE, Smith JM. Postoperative analgesia. Anaesthesia 1979;34:320-32.

${ }^{2}$ Snyder SH. Opiate receptors and internal opiates. Sci Am 1977;236:44-56.

${ }^{3}$ Epidural opiates. (Editorial) Lancet 1980;i:962-3. 
${ }^{4}$ Kitahata LM, Collins JG. Spinal action of narcotic analgesics. Anesthesiology 1981 ;54:153-63.

${ }^{5}$ Leslie J, Camporesi E, Urban B, Bromage P. Selective epidural analgesia. Lancet $1979 ;$;i :151.

${ }^{6}$ Scott DB, McClure J. Selective epidural anesthesia. Lancet $1979 ; \mathbf{i}: 1410$.

' Glynn CJ, Mather LE, Cousins MJ, Wilson PR, Graham JR. Spinal narcotics and respiratory depression. Lancet 1979 ;ii:356-7.

8 Weddel SJ, Ritter RR. Serum levels following epidural administration of morphine and correlation with relief of post-surgical pain. Anesthesiology 1981; 54:210-4.

${ }^{9}$ Reiz S, Ahlin J, Ahrenfeldt B, Andersson, M, Andersson S. Epidural morphine for postoperative pain relief. Acta Anaesth Scand $1981 ; 25: 111-4$.

${ }^{10}$ Behar M, Magora F, Olshwang D, Davidson JT. Epidural morphine in treatment of pain. Lancet $1979 ;$ i:527-9.

11 Wolfe MJ, Nicholas ADG. Selective epidural analgesia. Lancet 1979; ;i:150-1.

12 Graham JL, King R, McCaughey W. Postoperative pain relief using epidural morphine. Anaesthesia 1980;35:158-60.

${ }^{13}$ Bromage PR, Campresi E, Chestnut D. Epidural narcotics for postoperative analgesia. Anesth Analg (Cleve) 1980;59:473-80.

14 Ebert J, Varner PD. The effective use of epidural morphine sulphate for postoperative orthopedic pain. Anesthesiology 1980;53:257-8.

${ }^{15}$ Chayen MS, Rudick V, Borvine A. Pain control with epidural injection of morphine. Anesthesiology $1980 ; 53: 338-9$.
${ }^{16}$ Asari H, Inoue K, Shibata T, Soga T. Segmental effect of morphine injected into the epidural space in man. Anesthesiology $1981 ; 54: 75-7$.

17 Layfield DJ, Lemberger RJ, Hopkinson BR, Markin GS. Epidural morphine for ischaemic rest pain. Br Med J 1981 ;282:697-8.

18 Johnston JR, McCaughey W. Epidural morphine: a method of management of multiple fractured ribs. Anaesthesia 1980;35:155-7.

${ }^{19}$ Husemeyer RP, O'Connor MC, Davenport HT. Failure of epidural morphine to relieve pain in labour. Anaesthesia 1980;35:161-3.

${ }^{20}$ Booker PD, Wilkes RG, Bryson THL, Beddard J. Obstetric pain relief using epidural morphine. Anaesthesia 1980;35:377-9.

21 Writer WDR, James FM, Wheeler AS. Double blind comparison of morphine and bupivicaine for continuous epidural analgesia in labor. Anesthesiology 1981 ;54:215-9.

${ }^{22}$ McClure JH, Chambers WA, Moore E, Scott DB. Epidural morphine for postoperative pain. Lancet 1980;i:975-6.

${ }^{23}$ Teddy PJ, Fabinyi GCA, Kerr JH, Briggs M. Bupivicaine infiltration after lumbar laminectomy. Local infiltration with bupivicaine in the control of early postoperative lumbar laminectomy pain. Anaesthesia 1981 ;36:380-3.

${ }^{24}$ Revill SI, Robinson JL, Rosen M, Hogg MI. The reliability of a linear analogue scale for evaluating pain. Anaesthesia 1976;31:1191-8.

${ }_{25}$ McQuay HJ, Bullingham RES, Evans PJD, Lloyd JW, Moore RA. Demand analgesia to assess pain relief from epidural opiates. Lancet 1980;i:768-9. 